\title{
Retraction
}

The article titled, "C4d deposition in native kidney disease and its correlation with proteinuria and serum urea/creatinine", published in the International Journal of Research in Medical Sciences, Volume 6, Issue 12, 2018, Pages 3935-3941, DOI: http://dx.doi.org/10.18203/2320-6012.ijrms20184886 is being retracted. We received complaint from one of the co-authors, after publication of the article that corresponding author, Dr. Sant Pandey had submitted the manuscript without informing other co-authors and it was not his original work. We contacted the corresponding author who could not satisfactorily respond to our queries. Since the author could not satisfactorily defend his paper and contravened the declaration he made while submitting his manuscript, it was decided to retract the article from International Journal of Research in Medical Sciences and not to consider any manuscript submitted by him in future. 


\title{
Original Research Article
}

\section{C4d deposition in native kidney disease and its correlation with proteinuria and serum urea/creatinine}

\author{
Sant Pandey ${ }^{1 *}$, Sucheta Yadav ${ }^{2}$, Suresh Babu², Ashutosh Kumar', Bhupendra P. Singh ${ }^{3}$, \\ Anupam Wakhlu ${ }^{4}$, Atin Singhai ${ }^{2}$, S. K. Sonkar ${ }^{5}$, Vishal Pooniya ${ }^{6}$
}

\begin{abstract}
${ }^{1}$ Department of Nephrology, ${ }^{2}$ Department of Pathology, ${ }^{3}$ Department of Urology, ${ }^{4}$ Department of Rheumatology, ${ }^{5}$ Department of Medicine, ${ }^{6}$ Department of Pediatrics, King George's Medical University, Lucknow, Uttar Pradesh, India
\end{abstract}

Received: 17 August 2018

Revised: 11 October 2018

Accepted: 13 October 2018

\author{
*Correspondence: \\ Dr. Sant Pandey, \\ E-mail: santimsbhu@gmail.com
}

Copyright: () the author(s), publisher and licensee Medip Academy. This is an open-access article distributed under the terms of the Creative Commons Attribution Non-Commercial License, which permits unrestricted non-commercial use, distribution, and reproduction in any medium, provided the original work is properly cited.

\begin{abstract}
Background: C4d is a well-known biomarker of the complement cascade. It is derived from cleavage of the labile thioester bond of $\mathrm{C} 4 \mathrm{~b}$. This cleavage provides $\mathrm{C} 4 \mathrm{~d}$ a covalent bond which helps $\mathrm{C} 4 \mathrm{~d}$ to anchor to nearby cells where immune complexes are deposited. Antibodies dissociate naturally because of relatively weak hydrostatic and Van der Waals forces between antigens and antibodies, whereas covalent bond of $\mathrm{C} 4 \mathrm{~d}$ has a much longer half-life. For this reason, $\mathrm{C} 4 \mathrm{~d}$ serves as a footprint of complement activation.

Methods: This was a retrospective and prospective cross-sectional study, done at our tertiary care hospital.

Results: Authors evaluated 50 cases and 10 controls to adjudge the significance of C4d deposits in native renal diseases. Majority of the patients (44\%) were in the age group of 10-20 years followed by $20 \%$ in the age group of $31-40$ years. $62 \%$ of study population were male. Majority of patients were diagnosed with FSGS (16\%), followed by membranous nephropathy (14\%), lupus nephropathy (14\%) and IgA nephropathy (12\%). There was correlation of intensity expression of glomerular C4d deposits with presenting 24 hours urinary protein level at the time of biopsy (p value $=0.027$ ) but no correlation with urea/creatinine.

Conclusions: All patients diagnosed with membranous nephropathy, IgA nephropathy and hypertensive nephropathy showed glomerular C4d deposits, and also diagnosed with IgA nephropathy, post infectious glomerulonephritis, lupus nephritis, minimal change disease, acute/chronic tubulointerstitial nephritis, diabetic nephropathy, hypertensive nephropathy showed tubular $\mathrm{C} 4 \mathrm{~d}$ deposits. All patients diagnosed with diabetic nephropathy and hypertensive nephropathy showed arterial $\mathrm{C} 4 \mathrm{~d}$ deposits.
\end{abstract}

Keywords: Chronic kidney disease, Focal segmental glomerular sclerosis, IgAN-IgA nephropathy, Lupus nephritis

\section{INTRODUCTION}

$\mathrm{C} 4 \mathrm{~d}$ is a well-known biomarker of the complement cascade. It is derived from cleavage of the labile thioester bond of $\mathrm{C} 4 \mathrm{~b}$. This cleavage provides $\mathrm{C} 4 \mathrm{~d}$ a covalent bond which helps $\mathrm{C} 4 \mathrm{~d}$ to anchor to nearby cells where immune complexes are deposited. Antibodies dissociate naturally because of relatively weak hydrostatic and Van der Waals forces between antigens and antibodies, whereas covalent bond of $\mathrm{C} 4 \mathrm{~d}$ has a much longer half-life. For this reason, $\mathrm{C} 4 \mathrm{~d}$ serves as a footprint of complement activation. The utility of $\mathrm{C} 4 \mathrm{~d}$ in the identification in the Banff classification in 2003.

Recently, many researchers have turned their attention to C4d deposition in native renal diseases. Xing et al, 
investigated that complement activation is involved in renal damage of pauci-immune crescentric glomerulonephritis. ${ }^{1}$ Espinosa-Hernandaz et al, suggested that $\mathrm{C} 4 \mathrm{~d}$ is a useful tool for the differential diagnosis of membranous nephropathy and minimal change disease. ${ }^{2}$ Negative mesangial C4d staining in glomeruli in patients with $\operatorname{IgA}$ nephropathy helps to identify patients with good long term prognosis for whom aggressive treatment is not required. Also, positive staining in tubular epithelium significantly correlates with a higher grade of WHO classification. ${ }^{3}$

However, very little information is available on the pathogenesis of various diseases that are activated by the compliment system. Therefore, it is reasonable to expand the study of $\mathrm{C} 4 \mathrm{~d}$ to other immunologic diseases to prove $\mathrm{C} 4 \mathrm{~d}$ deposition on immune complexes and to find a new role of $\mathrm{C} 4 \mathrm{~d}$ in other diseases.

Aims and objectives was to investigate the role of $\mathrm{C} 4 \mathrm{~d}$ deposition in native renal diseases and to establish the correlation of its expression with varying histologic grades of the disease. Also, to analyze and correlate urine protein excretion, serum urea and serum creatinine in patients with follow up.

\section{METHODS}

\section{Study design}

A retrospective and prospective cross-sectional study was done at this tertiary care hospital. The sample was collected with adequate patient's clinical information, proper consent and processed routinely. Each renal tissue was stained with hematoxylin and eosin, periodic acid Schiff along with silver methanamine and Masson's Trichome stain as and when required, examined and findings interpreted to make a definite diagnosis. Further immunohistochemical staining for $\mathrm{C} 4 \mathrm{~d}$ was done and interpreted.

\section{Duration of study}

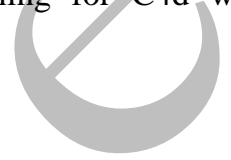

- Retrospectively-From January 2016 to July 2016,

- Prospectively-From August 2016 to February 2017,

- Follow up-each case was followed up for 6 months.

\section{Sample size}

Sample size was calculated with $95 \%$ confidence in interval estimation, $15 \%$ anticipated range from previous studies and $10 \%$ absolute error of margin by using formula:

$\mathrm{n}=\mathrm{Z}^{2} \pi(1-\pi) / \mathrm{d}^{2}$

\section{Where,}

$\mathrm{Z}=$ Table value of alpha error from standard normal distribution table (1.96 for $95 \%$ confidence interval), $\pi=$ anticipated range (from previous studies),

$\mathrm{d}=$ the absolute precision required on either side of true value of the population proportion $\pi$,

Population proportion $=\mathrm{V}=15 \%=0.15$,

Level of significance (alpha error) $=5 \%$,

Margin of error $=\mathrm{d}=0.1$,

Confidence interval $=95 \%$.

$\mathrm{n}=(1.96)^{2} \times 0.15 \times 0.85 /(0.1)^{2}$

Thus, minimum sample size was decided to be 50 . Authors evaluated 50 cases and 10 controls with follow up.

\section{Inclusion criteria}

All the diagnosed and suspected cases of native renal disease.

\section{Exclusion criteria}

All the known cases of renal transplant and/or established renal neoplasm.

\section{Case defination}

All diagnosed cases of native renal disease.

\section{Control definition}

- Autopsy/cadaveric specimen of kidney showing unremarkable histology and few other cases with unremarkable glomeruli as a negative control.

- Renal graft section from a kidney transplant patient with antibody mediated rejection as a positive control.

\section{Statistical analysis}

Quantitative data is presented with the help of mean and standard deviation. Comparison among the study groups is done with the help of unpaired t test as per results of normality test. Qualitative data is presented with the help of frequency and percentage table. Association among the study groups is assessed with the help of Fisher test, student ' $\mathrm{t}$ ' test and Chi-Square test. ' $\mathrm{p}$ ' value less than 0.05 is taken as significant.

\section{RESULTS}

A total of patients (50 cases and 10 controls) were studied to adjudge the significance of $\mathrm{C} 4 \mathrm{~d}$ deposits in native renal diseases across Indian cohort of patients.

\section{Distribution of patients according to age}

Majority of the patients $(44 \%)$ were in the age group of $10-20$ years followed by $20 \%$ in the age group of $31-40$ years, $12 \%$ in the age group of 21-30 years, $10 \%$ in the 
age group of 41-50 years, $8 \%$ in the age group of 51-60 years and $6 \%$ in the age group of 61-70 years. The mean age of the patients was $29.4 \pm 16.60$ years. Majority of patients $(16 \%)$ were diagnosed with focal segmental glomerulosclerosis (16\%) followed by membranous nephropathy (14\%) lupus nephritrits (14\%) and IgA nephropathy $(12 \%)$.
The association of glomerular $\mathrm{C} 4 \mathrm{~d}$ deposition and disease group is characterized in Table 2 .

All patients diagnosed with membranbous nephropathy, IgA nephropathy and hypertensive nephropathy showed glomerular C4d deposits.

Table 1: Distribution of patients according to histopathological diseases and C4d staining pattern.

\begin{tabular}{|c|c|c|c|c|c|c|}
\hline \multirow{3}{*}{ Disease Group } & \multicolumn{4}{|c|}{ Glomerular C4d Deposition } & \multirow{3}{*}{ Total } & \multirow{3}{*}{ p value } \\
\hline & \multicolumn{2}{|c|}{ C4d positive } & \multicolumn{2}{|c|}{ C4d negative } & & \\
\hline & $\mathrm{N}$ & $\%$ & $\mathrm{~N}$ & $\%$ & & \\
\hline Focal segmental glomerulosclerosis & 0 & - & 8 & $100 \%$ & 8 & 0.168 \\
\hline Membranous nephropathy & 7 & $100 \%$ & 0 & - & 7 & 0.163 \\
\hline Lupus nephritis & 3 & $43 \%$ & 4 & $57 \%$ & 7 & 0.137 \\
\hline IgA nephropathy & 6 & $100 \%$ & 0 & - & 6 & 0.123 \\
\hline Post infection glomerulonephritis & 2 & $40 \%$ & 3 & $60 \%$ & 5 & 0.174 \\
\hline Diffuse global sclerosis & 0 & - & 4 & $100 \%$ & 4 & 0.179 \\
\hline Minimal change disease & 0 & - & 4 & $100 \%$ & 4 & 0.113 \\
\hline acute/chronic tubulointerstitial nephritis & 0 & - & 3 & $100 \%$ & 3 & 0.119 \\
\hline Diabetic nephropathy & 1 & $50 \%$ & 1 & $50 \%$ & 2 & 0.171 \\
\hline Hypertensive nephropathy & 2 & $100 \%$ & & - & 2 & 0.121 \\
\hline Membranoproliferative glomerulonephritis & 1 & $50 \%$ & 1 & $50 \%$ & 2 & 0.137 \\
\hline Total & 20 & $40 \%$ & 30 & $60 \%$ & 50 & \\
\hline
\end{tabular}

Table 2: Association of tubular C4d deposition and disease group.

\begin{tabular}{|c|c|c|c|c|c|c|}
\hline \multirow{3}{*}{ Disease group } & \multicolumn{4}{|c|}{ Tubular C4d Deposition } & \multirow{3}{*}{ Total } & \multirow{3}{*}{ p value } \\
\hline & \multicolumn{2}{|c|}{ C4d Positive } & \multicolumn{2}{|c|}{ C4d negative } & & \\
\hline & $\mathbf{N}$ & $\%$ & $\mathbf{N}$ & $\%$ & & \\
\hline Focal segmental glomerulosclerosis & 1 & $12.5 \%$ & 7 & $87.5 \%$ & 8 & 0.194 \\
\hline Membranous nephropathy & 6 & 85.7 & 1 & $14.3 \%$ & 7 & 0.187 \\
\hline Lupus nephritis & 7 & $100 \%$ & 0 & - & 7 & 0.156 \\
\hline IgA nephropathy & 6 & $100 \%$ & 0 & - & 6 & 0.182 \\
\hline Post infection glomerulonephritis & 5 & $100 \%$ & 0 & - & 5 & 0.163 \\
\hline Diffuse global sclerosis & 0 & - & 4 & $100 \%$ & 4 & 0.185 \\
\hline Minimal change disease & 4 & $100 \%$ & 0 & - & 4 & 0.271 \\
\hline Acute/chronic tubulointerstitialnephritis & 3 & $100 \%$ & 0 & - & 3 & 0.251 \\
\hline Diabetic nephropathy & 2 & $100 \%$ & 0 & - & 2 & 0.208 \\
\hline Hypertensive nephropathy & 2 & $100 \%$ & 0 & - & 2 & 0.102 \\
\hline Membranoproliferative glomerulonephritis & 1 & $50 \%$ & 1 & $50 \%$ & 2 & 0.227 \\
\hline Total & 36 & $72 \%$ & 14 & $28 \%$ & 50 & \\
\hline
\end{tabular}

The association of arterial $\mathrm{C} 4 \mathrm{~d}$ deposition and disease group is characterized in Table 3. All patient diagnosed with diabetic nephropathy and hypertensive nephropathy (2 patients each) showed arterial C4d deposits.

\section{Association of C4d deposition and serum urea}

The baseline serum urea value between Glomerular, Tubular and Arterial $\mathrm{C} 4 \mathrm{~d}+$ and $\mathrm{C} 4 \mathrm{~d}-$ patients was statistically no significant.

\section{Association of C4d deposition in control patients}

Serum urea, creatinine, 24hour urinary protein value within $\mathrm{C} 4 \mathrm{~d}+$ and $\mathrm{C} 4 \mathrm{~d}-$ patients at 6 month follow up and baseline was statistically not significant.

\section{Association of C4d deposition and serum urea}

The baseline serum urea value between glomerular, tubular and arterial $\mathrm{C} 4 \mathrm{~d}+$ and $\mathrm{C} 4 \mathrm{~d}$-patients was statistically not significant. The baseline serum creatinine 
value between arterial $\mathrm{C} 4 \mathrm{~d}+$ and $\mathrm{C} 4 \mathrm{~d}$ patients was statistically not significant for glomerular and tubular $\mathrm{C} 4 \mathrm{~d}+$ and $\mathrm{C} 4 \mathrm{~d}-$ patients.

Association of C4d deposition and 24hours urinaryprotein
The level of baseline 24hours urinary-protien value for intensity of $\mathrm{C} 4 \mathrm{~d}$ positivity was statistically significant with $\mathrm{p}$ value $=0.027$.

The association of arterial C4d deposition and disease group is characterized in Table 3.

Table 3: Association of arterial C4d deposition and disease group.

\begin{tabular}{|c|c|c|c|c|c|c|}
\hline \multirow{3}{*}{ Disease Group } & \multicolumn{4}{|c|}{ Arterial C4d Deposition } & \multirow{3}{*}{ Total } & \multirow{3}{*}{ p Value } \\
\hline & \multicolumn{2}{|c|}{ C4d Positive } & \multicolumn{2}{|c|}{ C4d negative } & & \\
\hline & $\mathbf{N}$ & $\%$ & $\mathbf{N}$ & $\%$ & & \\
\hline Focal segmental glomerulosclerosis & 0 & - & 8 & $100 \%$ & 8 & 0.208 \\
\hline Membranous nephropathy & 0 & - & 7 & $100 \%$ & 7 & 0.161 \\
\hline Lupus nephritis & 1 & $25 \%$ & 6 & $75 \%$ & 7 & 0.177 \\
\hline IgA nephropathy & 0 & - & 6 & $100 \%$ & 6 & 0.192 \\
\hline Post infection glomerulonephritis & 0 & - & 5 & $100 \%$ & 5 & 0.109 \\
\hline Diffuse global sclerosis & 0 & - & 4 & $100 \%$ & 4 & 0.176 \\
\hline Minimal change disease & 0 & - & 4 & $100 \%$ & 4 & 0.146 \\
\hline Acute/chronic tubulointerstitial nephritis & 0 & - & 3 & $100 \%$ & 3 & 0.138 \\
\hline Diabetic nephropathy & 2 & $100 \%$ & 0 & - & 2 & 0.274 \\
\hline Hypertensive nephropathy & 2 & $100 \%$ & 0 & - & 2 & 0.176 \\
\hline Membranoproliferative glomerulonephritis & 0 & - & 2 & $100 \%$ & 2 & 0.178 \\
\hline Total & 5 & $10 \%$ & 45 & $90 \%$ & 50 & \\
\hline
\end{tabular}

Table 4: Association of C4d deposition and serum urea.

\begin{tabular}{|c|c|c|c|}
\hline \multirow{2}{*}{ C4d Deposition } & Serum Urea & & \multirow{3}{*}{ p value } \\
\hline & Mean & SD & \\
\hline Glomerular & 7 & $\checkmark$ & \\
\hline C4d Positive & 67.24 & 30.97 & \multirow{2}{*}{0.251} \\
\hline C4d Negative & 57.95 & 25.29 & \\
\hline \multicolumn{4}{|l|}{ Tubular } \\
\hline C4d Positive & 64.09 & 27.20 & \multirow{2}{*}{0.143} \\
\hline C4d Negative & 56.2 & 30.59 & \\
\hline Arterial & 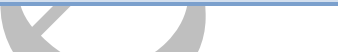 & & \\
\hline C4d Negative & 75.38 & 16.35 & \multirow{2}{*}{0.225} \\
\hline C4d Negative & 60.56 & 28.77 & \\
\hline
\end{tabular}

Table 5: Association of C4d deposition and serum creatinine.

\begin{tabular}{|llcl|}
\hline C4d & $\begin{array}{l}\text { Serum Creatinine } \\
\text { Mean }\end{array}$ & SD & p value \\
\hline Glomerular & & & 0.199 \\
\hline C4d Positive & 1.65 & 0.83 & 0.149 \\
\hline C4d Negative & 2.08 & 1.43 & \\
\hline Tubular & & & \multirow{2}{*}{0.004} \\
\hline C4d Positive & 1.79 & 0.85 & \\
\hline C4d Negative & 2.19 & 1.94 & \\
\hline Arterial & & & \\
\hline C4d Positive & 2.63 & 1.25 & \\
\hline C4d Negative & 1.81 & &
\end{tabular}




\section{DISCUSSION}

The age of patients ranged between 10-70 years with the mean age of $29.4 \pm 16.60$ years. Majority $(44 \%)$ of the patients were in the age group of 10-20 year. There was also male preponderance $(62 \%)$.

\section{Association of glomerular C4d deposits}

In this study intensity of glomerular C4d positivity showed a significant association ( $p$ value $<0.001$ ) with higher grade/class of disease like lupus nephritis. IgA nephropathy and membranous nephropathy, as seen with the study done by Min-Kyung Kim et al, which showed significant relationship between glomerular $\mathrm{C} 4 \mathrm{~d}$ deposition and the pathologic classes of lupus nephritis with a $p$ value $<0.001$. $^{4}$

In a study conducted by Hamid Nasri et al, in 2015 on 29 renal biopsies of patients with $\operatorname{IgAN}, 54.2 \pm 25 \%$ of all glomeruli were positive for $\mathrm{C} 4 \mathrm{~d} .{ }^{5}$ A retrospective study by Young-In Maeng et al, including 23 IgAN patients, showed that 13 patients $(56.5 \%)$ were positive for $\mathrm{C} 4 \mathrm{~d}$ staining in the glomerulus and 10 patients $(43.5 \%)$ were C4d negative. ${ }^{3}$

In a retrospective study by Espinosa et al, comprising of patients with $\operatorname{IgAN}$, they found that in 109 patients (38.5\%) glomerular staining for $\mathrm{C} 4 \mathrm{~d}$ was observed and $174(61.5 \%)$ were $\mathrm{C} 4 \mathrm{~d}$ negative. ${ }^{6}$ In a study conducted by Goncalves Fabiano RC et al, on 47 patients of $\operatorname{IgAN}, 14$ (29.8\%) had up to $20 \%$ positivity, 8 (17.0\%) had $20-40 \%$ positivity, $3(6.4 \%)$ had $40-60 \%$ positivity, $4(8.5 \%)$ had $60-80 \%$ of positivity, and $3(6.4 \%)$ had $80-100 \%$ of positivity, fifteen patients $(31.9 \%)$ did not show glomerular C4d deposits. ${ }^{7}$ In this study all of the $\operatorname{IgAN}$ cases show significant $\mathrm{C} 4 \mathrm{~d}$ positivity in the range $2+$ and more.

Study done by Espinosa et al, on 21 patients of membranous nephropathy showed glomerular C4d deposits in $100 \%$ patients. $^{2}$ In another study by Sepe V et al, on 15 patients of native idiopathic membranous nephropathy, 10 out of 15 kidney biopsies (66.6\%) showed glomerular capillary wall deposition of C4d (8).

A study conducted by Min-Kyung Kim et al, found that out of 20 cases of lupus nephritis glomerular C4d deposits were detected in 13 cases $(65 \%)$. Of the C4D positive cases, majority belong to class III and IV and that too particularly in association with class $\mathrm{V}$, as per ISN-RPS 2003 classification of lupus nephritis. ${ }^{4}$ Daram SR et al, studied patterns of C4d staining in cases of lupus nephritis. All 16 patients (100\%) showed deposition of $\mathrm{C} 4 \mathrm{~d}$ in the glomerular structures, and one also had focal deposition of $\mathrm{C} 4 \mathrm{~d}$ in the peritublar capillaries. ${ }^{9}$ In this study, 3 out of 7 cases (43\%) of lupus nephritis of various classes showed glomerular $\mathrm{C} 4 \mathrm{~d}$ positivity.
Authors encountered 2 cases of benign hypertensive nephropathy, both of which showed C4d positivity in nonsclerotic glomerular segments. This may be an incidental finding as no contributing factor for the same could be traced out.

In diabetic nephropathy, membranoproliferative glomerulonephritis and post infectious glomerulonephritis glomerular $\mathrm{C} 4 \mathrm{~d}$ positivity was in $50 \%, 50 \%$ and $40 \%$ of the respective cases. Focal segmental glomerulosclerosis diffuses global sclerosis, acute/chronic tubule-interstitial nephritis and minimal change disease showed no $\mathrm{C} 4 \mathrm{~d}$ deposits/nonspecific chromogen trappings in glomeruli. Study conducted by Val-Bernal JF et al, cases of different glomerulonephritis, including IgA nephropathy, membranoproliferative glomerulonephritis, focal segmental glomerulosclerosis and minimal change disease showed diverse pattern of $\mathrm{C} 4 \mathrm{~d}$ deposition without intrinsic background, which is in concordance with findings of our study. ${ }^{10}$

However, search of literature yielded few studies, Tanuma et al and Fremeaux-Bacchi V et al, which suggested possibility of accelerated decay of cell bound C4d2acomplex through activation of classical/lectin pathway by serum of patients with post-streptococcal acute glomerulonephritis. ${ }^{11,12}$ This may be aetiological factor too in $\mathrm{C} 4 \mathrm{~d}$ positive postinfectionus glomerulonephritis cases in our study.

For minimal change disease results of present study were in were in concordance with study done by Espinosa et al, on 21 patient of membranous nephropathy and 19 patient with minimal change disease showed glomerular C4d deposits in $100 \%$ patients of membranous nephropathy and no $\mathrm{C} 4 \mathrm{~d}$ deposits in minimal change disease. $^{2}$

Correlation of C4d deposits intensity verses 24hour urinary protein levels

Glomerular intensity was graded from 2 to $3+$ as described in material and methods section before, subsequently four subclasses were also framed as per presenting value of 24 hours protein. Group 1 comprised of $<2 \mathrm{gm}$, group п 2-4gm, group ш 4-6gm and group iv $>6 \mathrm{gm}$ of 24 hours urinary protein. Cross tabulation of the above-mentioned variables by Pearson Chi-Square test yielded significant $\mathrm{p}$ value of 0.027 .

A study done by Bose BM et al, and showed glomerular C4d positivity in 21 cases $(66.7 \%)$ of IgA nephropathy and significant association with nephritic range proteinuria ( $\mathrm{p}$ value 0.047 ). ${ }^{13}$ Another study by Maeng Y et al, including $23 \mathrm{IgAN}$ patients showed that the amount of albuminuria is significantly correlated with glomerular C4d staining. ${ }^{3}$ 
Correlation of C4d deposits intensity verses serum urea and creatinine

There was no significant association found between glomerular C4d positivity and presenting values of serum urea and creatinine at the time of biopsy.

\section{Association of tubular C4d deposits}

As per western literature, Maeng $\mathrm{Y}$ et al and Van Es La et al, positive epithelial C4d staining in tubules is associated with either or both of the following factors: higher histological grade and higher degree of interstitial inflammation. ${ }^{3,14}$ As peer Maenget $\mathrm{Y}$ et al, including 23 IgAN patients, showed that 11 out of 21 patients $(47.8 \%)$ were positive for $\mathrm{C} 4 \mathrm{~d}$ staining in the tubular epithelium, however $\mathrm{C} 4 \mathrm{~d}$ deposits in tubular epithelium of $\mathrm{MCD}$ group was not detected. ${ }^{3}$ However, there results turned out to be non-significant.

\section{Correlation of C4d deposits intensity verses 24hours urinary protein levels}

Our study revealed significant association ( $p$ value 0.019 ) of tubular C4d positivity with 24 hours urinary protein at the time of biopsy. This can be attributed to the fact as quoted above of fair number of cases presenting with higher histological grade. However, this finding was not in concordance with order literature searched Meang Y et al, which showed a non-significant association between these two variables. ${ }^{3}$

Correlation of C4d deposits intensity verses serum urea and creatinine

There is no significant association noted between tubular C4d deposits and presenting levels of serum urea and creatinine at the time of biopsy. This again could be attributed to the fact that tubulo-interstitial inflammation was a side accompanying feature of most of the cases in this study, which were diagnosed as primary/secondary glomerulonephritis on upfront. There were only 3 out of 50 cases which were primarily levelled as tubulointerstitial nephritis that show prominent tubular C4d deposits but with no statistical significance probably because of overlapping feature with other glomerulonephritis included in the study.

\section{Association of arterial C4d deposits}

In this study diabetic and hypertensive nephropathy showed prominent arterial C4d deposits. Study by Maeng $\mathrm{Y}$ et al, revealed arterial C4d deposit in high grade of $\operatorname{IgA}$ nephropathy. ${ }^{3}$ There is no specific correlation of arterial C4d deposit with 24hr. urinary protein and urea/creatinine.

Small sample size and limited duration follow up is major limitation in this study.

\section{CONCLUSION}

C4d deposits in various renal compartments viz. glomerular, tubular, arterial and peritublar capillaries were observed in relation with specific native renal diseases. For glomerular C4d deposits, all cases of membranous nephropathy, IgA nephropathy and hypertensive nephropathy showed positivity ranging from $2+$ to $3+$. Correlation of intensity expression of glomerular C4d deposits with presenting 24hours urinary protein level at the time of biopsy yielded significant results with $\mathrm{p}$ value of 0.027 but no correlation with urea/creatinine. The higher trend tubular C4d deposits can be attributing to contribution factors related to both higher histological grade and high degree of tubulointerstitial inflammation in most of cases included in our study and there is significant association ( $\mathrm{p}$ value 0.019) of tubular C4d positivity with 24 hour protein at the time of biopsy. Tubular C4d deposits showed no significant presenting serum urea and creatinine at the time of biopsy. Arterial C4d deposits were seen only in diabetic and hypertensive nephropathy in this study. There was also no correlation noted between presenting 24hours urinary protein and serum urea and creatinine levels.

Funding: No funding sources

Conflict of interest: None declared

Ethical approval: The study was approved by the Institutional Ethics Committee

\section{REFERENCES}

1. Xing GQ, Chen M, Liu G, Zheng X, Jie E, Zhao MH. Differential deposition of C4d and MBL in glomeruli of patients with ANCA-negative pauciimmune crescentic glomerulonephritis. J Clinical Immunol. 2010 Jan 1;30(1):144-56.

2. Espinosa-Hernández M, Ortega-Salas R, LópezAndreu M, Gómez-Carrasco JM, Pérez-Sáez MJ, Pérez-Seoane C, et al. C4d as a diagnostic tool in membranous nephropathy. Nefrologia. 2012 May 14;32(3):295-9.

3. Maeng YI, Kim MK, Park JB, Cho $\mathrm{CH}$, Oh HK, Park KK. Glomerular and tubular C4d deposition in IGA nephropathy: relation with histopathology and with albuminuria. Int $\mathbf{J}$ Clin Exp Pathol. 2013;6(5):904.

4. Kim MK, Maeng YI, Lee SJ, Lee IH, Bae J, Kang $\mathrm{YN}$, et al. Pathogenesis and significance of glomerular $\mathrm{C} 4 \mathrm{~d}$ deposition in lupus nephritis: activation of classical and lectin pathways. Inter $\mathbf{J}$ Clin Exp Pathol. 2013;6(10):2157.

5. Nasri H, Ahmadi A, Rafieian-kopaei M, Bashardoust B, Nasri P, Mubarak M. Association of glomerular $\mathrm{C} 4 \mathrm{~d}$ deposition with various demographic data in IgA nephropathy patients; a preliminary study. J Nephropathol. 2015 Jan;4(1):19. 
6. Espinosa M, Ortega R, Sánchez M, Segarra A, Salcedo MT, González F, et al. Association of C4d deposition with clinical outcomes in $\operatorname{IgA}$ nephropathy. Clin J Am Society Nephrol. 2014 Feb 27:CJN-09710913.

7. Fabiano RC, de Almeida Araújo S, Bambirra EA, Oliveira EA, e Silva AC, Pinheiro SV. Mesangial C4d deposition may predict progression of kidney disease in pediatric patients with IgA nephropathy. Pediatric Nephrol. 2017 Jul 1;32(7):1211-20.

8. Sepe V, Albrizio P, Canton AD. C4d Glomerular Deposits and Disease Progression in Native Idiopathic Membranous Nephropathy. J Nephrol Ther. 2015;5(212):2161-0959.

9. Daram SR, Yalamanchili P, Salinas-Madrigal L, Bastani B. Patterns of C4d staining in patients with lupus nephritis. J Appl Res Clin Exp Ther. 2006;6(2):176.

10. Val-Bernal JF, Garijo MF, Val D, Rodrigo E, Arias M. C4d immunohistochemical staining is a sensitive method to confirm immune-reactant deposition in formalin-fixed paraffin-embedded tissue in membranous glomerulo-nephritis. Histol Hi. 2011;26(10):1391.

11. Trnuma Y Ohi H, Hatono M. Accelerated decay of the cel bound C4b2a complex by serum of patients with membranoproliferative glomerulonephritis and acute poststreptococcal glomerulonephritis. Clin Immunol Immunopathol. 1992;62(3):270-6.

12. Freneaux-Bacchi V, Weiss L, Demouchy C, May A, Palomera S, Kazatichkine MD. Hypocomlementaemia of poststreptococcal acute glomerulonephritis is associated with $\mathrm{C} 3$ nephritis factor (C3NeF) IgG autoantibody activity. Nephrol Dialysis Trans. 1994;9(12):1747-50.

13. Bose BM, Pothen L, Parameswaran JK Poothiode U. Clinicopthological comparative study of $\mathrm{C} 4 \mathrm{~d}$ positive and negative cases og $\operatorname{IgA}$ nephropathy. Immunopathologia Persa. 2016 Sep 19;3(1).

14. Van Es LA, De Heer E, Vleming LJ, Van Der Wal A, Mallat M, Bajema I, et al. GMP-17-positive Tlymphocytes in renal tubules predict progression in early stages of $\operatorname{IgA}$ nephropathy. Kidney international. 2008;73(12):1426-33.

Cite this article as: Pandey $\mathrm{S}$, Yadav $\mathrm{S}, \mathrm{Babu} \mathrm{S}$, Kumar A, Singh BP, Wakhlu A, et al. C4d deposition in native kidney disease and its correlation with proteinuria and serum urea/creatinine. Int J Res Med Sci 2018;6:3935-41. 